\title{
The Doctor Patient Relationship: A Calculus of Two Languages? A Glimpse at VKH Disease Through the Doctor Patient Relationship
}

\author{
Joseph W Eichenbaum* \\ Adjunct Associate Professor of Ophthalmology and Pharmacology, Icahn School of Medicine at Mount Sinai, USA
}

Submission: December 12, 2019; Published: January 22, 2020

*Corresponding author: Joseph W Eichenbaum, Adjunct Associate Professor of Ophthalmology and Pharmacology, Icahn School of Medicine at Mount Sinai, Gustav Levy Place, USA

\author{
Abstract \\ through the respective languages of the doctor and the patient under the lens of time. \\ Keywords: Doctor patient relationship; Calculus over time; Abettors; Disruptors; VKH Disease
}

Human feelings have been an integral part of the doctor patient relationship from early medical history. Recently, in addition, the role of language of the doctor and the patient has come under scrutiny. In this paper the ebb and flow of the doctor patient relationship is examined

Abbreviation: VKH: Vogt Koyanagi Harada's Disease

\section{Introduction}

\section{Feelings in Medicine}

Hippocrates, (460-370 BC) was the first physician to place the origins of thoughts, ideas, and feelings in the brain and not the heart. Galen, (126-216) despite his loyalty to humoralism advocated by Hippocrates, was known for his differential diagnosis and emphasized the difference between organic versus emotional diagnosis. Maimonides (1135-1204) believed that passions produce great changes in the body and that the perturbations of the psyche need to be in balance to help serve as a check on disease. Thus, the beginnings of medical science captured the significance of human feelings as one of the essential parts of disease [1].

\section{Evolution of Two Languages}

The patient in one language or another has for over two millennia complained of pain or some other feelings of illness in a basic human language to the physician. Over the course of time, however, because of the evolution of voluminous areas of knowledge in medicine, the physician has developed his/her own language. Consequently, there has emerged a dichotomy of language used by the patient and the physician. In addition, the culture, native language, and geographic location have been noted as other problems for the patient side of the equation [2-6].

\section{The Math of Change Over Time}

Calculus, a branch of math that looks at changes between two elements and gives them a relationship either by dividing them into smaller pieces, (differential calculus) or by adding smaller pieces together, (integral calculus) helps us look at change over time. In considering the doctor patient relationship it is the changes over time or how the patient's language varies from that of the physician that can be seen either in terms of constructive additions or by divisive breaks. Not that those divisive breaks necessarily spell the end of the relationship or that those smaller piece additions insure its perpetuation, but rather there is an ebb and flow, which punctuates the course of the relationship. It is the calculus of the two different languages, with an interpreter or without, of the doctor and the patient that will be explored in this essay.

\section{Key Feelings: Abettors and Disruptors}

What are some of the emotions or feelings that enable the languages of inception and evolution of the doctor patient relationship? The patient must be comfortable with the doctor's ability to listen with an open mind, be kind and considerate, putting his/her own preconceived notions aside, especially when first hearing the patient's anguish, sometimes even in the face of conflicting feelings and symptoms of illness. 
The doctor must submerge his/her need to offer quick diagnosis and treatment until the patient has had a chance to feel that he or she can respect and trust the physician and accept what the physician has to offer. These elements of trust and acceptance are the cornerstone to all future communication. The next doctor patient language rift is that of understanding. While the doctor digests the symptoms, signs and emotions of the patient from the history, physical, and lab data, the patient may be in a state of limbo about exactly what is the name of his/her problem and course of treatment. It then behooves the doctor to offer the patient some options regarding his/her understanding, some possible diagnosis, further testing and potential courses of management and time considerations. If the doctor can put the patient into some level of ease to weather the initial clouds of doubt hanging over the diagnosis and treatment, then this will initiate a language of compatibility. This can dispel much of the anxiety sometimes raised by family, friends and other confounders such as generalities about similar diseases from the media or the Internet. Moreover, if this language of compatibility is strong enough, then the role of additional consultants, diagnostic tests, and even treatment can ensue. However, this all comes to a crossroads in the discussion of medical insurance coverage. Like many areas of our lives, the power of the purse plays an important role. Here, even if the physician has more than adequately achieved the acceptance and trust of the patient as well as the compatibility for future communication, all too often one can hear the patient complain that the doctor does not accept the insurance at some or all levels of care. This is the language of disruption of the doctor patient relationship. Another disruption to the doctor patient relationship is the computer. Patients often complain that while the doctor seems to be listening, the doctor is facing the computer with his/her head down or his/her back towards them. See table 1 for abettors and disruptors of doctor patient relationship.

Table 1: Doctor Patient Relationship.

\begin{tabular}{|c|c|}
\hline Abettors & Disruptors \\
\hline Language & Insurance Acceptance \\
\hline Trust & Drug/device approval \\
\hline Respect & Computer Interference \\
\hline Mutual understanding & improper personal feelings \\
\hline
\end{tabular}

Probably one of the most serious disruptors of the doctor patient relationship is the malfeasance suggested by George Bernard Shaw in the Doctor's Dilemma, where favorites are played related to the doctor's personal feelings. Alternatively, the relationship can be ruptured if the doctor somehow commits an error in the dosage or type of medicine or even the diagnosis.

Thus, in the times we live, the doctor patient relationship often rests on precarious grounds, with an uncertain alchemy of feelings, emotions, and economics. So, the differences in language between the doctor and the patient as well as the many unknown curves in the road to disease management create a significant challenge to the science as well as the art of medicine.

\section{A Clinical Case}

In the following clinical case of Vogt Koyanagi Harada disease some of the vicissitudes of the doctor(s) patient relationship are manifest. A 28 year old Asian male from the Philippines who was working as a salad chef at one of the upper West Side restaurants and who was otherwise in excellent health with no prior medical history presented to a university hospital ER with bilateral painful blurry vision, headache, stiff neck, some trouble hearing, weakness, fevers and joint pain of two day's duration. Physical exam by the admitting medical resident revealed a mildly pigmented, thin, weak young man with a fever of 102 degrees F, pulse 86, BP 150/90, respirations 10 and somewhat labored. The skin had some areas along the chest and arms with mild depigmentation, some whitening and erythematous blotches. The pupils were only sluggishly reactive to light and the patient was quite photophobic. There was 2-3+ conjunctival injection and a small hypopion bilaterally. After several attempts at funduscopy, all that the medical resident could see was white lines radiating from the optic nerves and was not sure if there was bilateral papilledema. Hearing, tested by a small bell ringing on the side of each ear, was moderately diminished. There was mild stiffness of the neck to forward and backward movement with considerable pain. Similarly, there was considerable pain to arm elevation, bending at the elbow, and making a fist bilaterally. The patient could barely sit up in bed, let alone get out of bed and walk. The remainder of the exam was unremarkable. Struck by the fever, the CNS findings, the depigmentation, the suggestive uveitis signs and the stiff neck and joints, the medical resident explained to the patient that he might have some infection or inflammatory disease in his body and brain and would have to be admitted to the Neurology Unit of the hospital that night for evaluation by Neurology, Rheumatology, Ophthalmology, Dermatology and Medicine. When asked by the patient what was the name of the disease that the medical resident thought he had, the doctor answered in a sympathetic tone VKH or some type of meningitis. The patient then queried, "Is VKH a familial disease?" The doctor thought for a moment and then answered in the affirmative. The patient said that he could remember one of his cousins having something similar when he was younger. The doctor took his hand and explained that he would need to think about having some tests on his spinal fluid for pigment and white cells to be clearer on the diagnosis, but that there were some good ways of treating the disease with reasonable hope of recovery. "Yes, the patient said, I remember my cousin got better. He was also taken care of in this hospital." Much to the patient's chagrin, (The patient's name was Juan.) he would never see the ER medical resident again but retained a fond place in his heart for that first doctor. 
Juan dozed off and on awakening found that he was being asked to sign a consent to have pictures taken of his head in a noisy magnetic machine. He signed and a voice nearby clutching his hand asked him to hold still so the pictures of his head could come out. The next thing he knew he was asked to sign consent to have a needle placed in his back to check for infection, inflammation, white cells and pigment in his spinal fluid. He remembered the ER doctor's telling him about this and signed the consent. There was some pain from the needle in his back, but his eyes were burning so much, and he had such pain in his joints that he barely felt the needle. Some time passed and he heard a woman's voice introducing herself as the eye doctor on call; she apologized that it was one AM but because of the threat to his vision with the possible VKH she was called to see him as an emergency. She asked him to read some letters from a hand card with each eye, which he struggled with and then she shined a light into each eye to examine the back of the eyes. She explained to Juan that he had some large white spots around his optic nerves in his retina, which likely represented white cell inflammation and deposits and a little bit of fluid swelling of the optic nerves. She said that it did appear to be VKH which had affected the front and back of the eyes.

She went on that if it were left untreated the structures of the eye would swell, inflame, scar and have irreparable damage. She suggested that prompt treatment at least to the front of the eye with drops that relaxed the muscles and reduced inflammation would help not only the ocular pain but also help the vision and reduce scarring. Juan consented to the drops and she said that she would return in the daytime to check him and they would consider oral medicine to stop the swelling in the back of his eyes and brain, if the spinal tap tests were positive and if no other tests showed bad infections like tuberculosis. She pointed to a quiet site on his left forearm where someone had drawn a circle around a tuberculosis test. He liked her immediately and thanked her.

The next morning, Juan was barely awake at 7AM when an august team of physicians in white coats came to his bedside and said that they were from Neurology. They seemed to be talking to themselves as if he were not there and when he asked what they thought about him they seemed to innocently go on with their conversation amongst themselves in hushed tones as if he had not asked anything. They seemed to be rather pleased with one of the younger doctors who was reading from a slip of paper he had produced during their conversation. One neurology doctor asked him to sit up and shined a light in his eyes, looked into the back of his eyes and tapped on his knees with a little rubber hammer. They were gone in a few minutes and he dozed off.

About an hour later, an elderly doctor came to him and introduced himself as the Rheumatology doctor to check his body and joints. This doctor listened to Juan tell his story, examined Juan fully, and explained the multiple problems that VKH might pose currently and in the future. The rheumatologist explained that with the white cells and pigment found in the spinal fluid, from early this morning, it was quite likely that VKH was the diagnosis. That meant that multiple areas of the body had acquired an excess number of white cell and giant white cell aggregates that could attack his eyes, ears, brain, skin and other parts of his body. Unfortunately, these white cell aggregates carried the potential for vision, hearing and other brain damaging issues that could be irreversible unless high dose anti-inflammatory steroid injections were started today and ultimately adjusted over the next few weeks to oral steroid treatment maintenance. When his usual white cell levels returned and the eyes and ears and brain cleared, the steroid could be tapered and eventually stopped.

The doctor also said that the steroids could have long term effects on his bones, blood sugar levels, weight, sleeping pattern, and intensity of mental agitation (or even the reverse) depression. Juan said that he thought that white cells were good and could fight diseases. The doctor explained that as with most things in the body it is the right balance of white cells that helps. Overages of white cells, especially in the brain could be lethal. Then Juan asked the doctor if there were other medications that could be used that did not have such strong side effects. He was especially concerned about feeling wired. He said that his work in the kitchen was high pressure enough. He didn't know if he could work with more pressure. The doctor said that there were some newer antibody medicines that were considerably more expensive, that moderated the white cells, but they might create their own problems, such as infections or white cell tumor growth. As to the mental agitation, the doctor explained that after the steroids curtailed the white cell surges in the body, they would be tapered and even stopped. If he still needed them, they would talk about anti-anxiety medications to carry him through the steroid withdrawal.

The doctor said that he expected Juan to be in the hospital for a week and that his wife and his son could visit later today. Juan grew teary eyed and grabbed the old doctor and hugged him.

\section{A Calculus of the Doctor(s) Patient Relationship}

Fast forward...it is the end of the week in the hospital. Juan's vision has returned by about $85 \%$; he has no pain in his eyes; his hearing is slowly improving; his headache and stiff neck are gone and his joints are normal; he is on $40 \mathrm{mg}$ per day of Prednisone by mouth, twice a day after meals, prednisone eye drops every 4 hours in each eye, and has begun to drink a glass of milk twice a day for calcium and take walks three times a day. His wife arrives to take him home where he will have to recuperate for a week and pending clinic follow-ups then he will be able to return to work.

His discharge papers are in order and he is ready to leave when one of the nurses gives him a clipboard with his medication instruction sheet as well as his clinic follow up instructions. On another half sized sheet, the hospital asks him to fill out an 
evaluation on each doctor involved in his care. The possible ratings for each are: excellent, good, acceptable, poor, unacceptable. He fills it out as follows: ER doctor: good; Neurology doctors: poor; (never really listened to me or spent time); Ophthalmology doctor: good; Rheumatology doctor: excellent (listened to me and checked me every day, answered my questions and cared about me); Dermatology doctor: cannot recall such a doctor; Medical Doctor: cannot recall such a doctor. The medical chart may reflect the presence of all the listed doctors, but as far as the patient's concept of the relationships, he could only respond to those he had some feelings for or some experience with.

\section{Conclusion}

This essay is not meant as a solution to the problems of the doctor patient relationship but rather an illustration of the different feelings and languages that need to be considered both from the spoken side and the listening side so that a fair and balanced relationship can survive and produce a useful outcome for the joint efforts of the doctor and the patient.

\section{Acknowledgement}

To the late Dr. Morris Dillard who was a kind and thoughtful tutor and role model in caring for patients in internal medicine at
Yale New Haven Hospital; To the late Dr. Steven Podos who was chair of the Dept of Ophthalmology at Mount Sinai over thirty years and who shared so many insights over the management of "patients who came to us between the rock and the hard place" and last but not least, to the late Rabbi, Dr. Emanuel Rackman who taught me about tolerance and kindness to others from my earliest days that I can remember.

\section{References}

1. Sternberg EM (1996) History of Medicine, Emotions and Disease, the Balance of Passions, NIH, US National Library of Medicine.

2. Ferguson WJ, Candib LM (2002) Culture, language, and the doctorpatient relationship Fam Med 34(5): 353-361.

3. Partida Y (2007) Language barriers and the patient encounter, Virtual Mentor 9(8): 566-571.

4. Dietsche E (2017) When language is a barrier in the doctor patient relationship, the gap in Washington DC Minneapolis, and Boston, Doximity.

5. Manassis K (1986) The effects of cultural differences on the physician patient relationship, Can Fam Physician 32: 383-389.

6. Buchwald H (2019) The doctor patient relationship as defined by language. Clinical Oncology.

\begin{tabular}{|l|}
\hline \multicolumn{1}{|c|}{ Your next submission with Juniper Publishers } \\
will reach you the below assets \\
- Quality Editorial service \\
- Swift Peer Review \\
- Reprints availability \\
- E-prints Service \\
- Manuscript Podcast for convenient understanding \\
- Global attainment for your research \\
- Manuscript accessibility in different formats \\
( Pdf, E-pub, Full Text, Audio) \\
- Unceasing customer service \\
Track the below URL for one-step submission \\
https://juniperpublishers.com/online-submission.php \\
\hline
\end{tabular}

